\title{
Relationship of Workaholism with Stress and Job Burnout of Elementary School Teachers
}

\author{
Hossein Jenaabadi' ${ }^{1}$, Bahareh Azizi Nejad ${ }^{2}$, Fatemeh Saeidi Mahmoud Abadi ${ }^{3}$, \\ Rezvan Haghi ${ }^{4}$, Maryam Hojatinasab ${ }^{5}$ \\ ${ }^{1}$ Faculty of Educational Sciences and Psychology, University of Sistan and Baluchestan, Zahedan, Iran \\ ${ }^{2}$ Department of Educational Science, Payame Noor University, Tehran, Iran \\ ${ }^{3}$ Islamic Azad University, Tehran, Iran \\ ${ }^{4}$ Allameh Tabatabai University, Tehran, Iran \\ ${ }^{5} \mathrm{MA}$ of Educational Research, University of Sistan and Baluchestan, Zahedan, Iran \\ Email: hjenaabadi@ped.usb.ac.ir, Bahareh19@gmail.com
}

Received 7 June 2015; accepted 3 November 2015; published 6 January 2016

Copyright (C) 2016 by authors and Scientific Research Publishing Inc.

This work is licensed under the Creative Commons Attribution International License (CC BY).

http://creativecommons.org/licenses/by/4.0/

(c) (i) Open Access

\begin{abstract}
Teachers voluntarily devote a lot of time to their vocational activates. This can lead to workaholism and may result in stress and job burnout. The main objective of the current study is to examine the relationship of workaholism with stress and job burnout of elementary school teachers in Zahedan. This is a descriptive-correlational study. The sample includes 350 elementary school teachers in Zahedan whom are selected through applying stratified random sampling method and are examined using questionnaires on workaholism, occupational stress, and job burnout. To analyze the obtained data, correlation coefficient and simultaneous multiple regression analysis are applied using SPSS $_{21}$. Teachers' mean scores on workaholism, stress and job burnout are higher than the considered theoretical mean. Workaholism and its components (feeling of being driven to work, work involvement, and work enjoyment) are significantly and positively related to job burnout and occupational stress $(p<0.01)$. The results of simultaneous multiple regression analysis indicate that components of workaholism can predict teachers' occupational stress and job burnout $(p<0.05)$. Considering the results, holding training courses for teachers to become familiar with the phenomena of workaholism, stress, and job burnout, individual and organizational outcomes, methods of dealing with them and managing them effectively is highly recommended.
\end{abstract}

\section{Keywords}

Workaholism, Occupational Stress, Job Burnout, Elementary School Teachers 


\section{Introduction}

Attendance at workplace, spending considerable amount of time doing a job, and concerns about and mental preoccupations with occupational activities lead people to voluntarily devote a lot of time to their vocational activates without having adequate rest and recreation and dedicating enough time to family and friends. These people usually experience a lot of stress and their work may cause physical and mental problems for them. These people are known as workaholics and this trait is referred to as workaholism [1]. Studies on workaholism have provided different and contradictory results. As an instance, some researchers examined workaholism with a positive attitude and concluded that workaholics were very satisfied and productive; however, others had a negative viewpoint and considered workaholism as a non-fun phenomenon which caused various difficulties for others (an individual's colleagues) [2]. As Askari and Nouri noted, Piotrowski and Vodanovich asserted that when workaholic behaviors were excessive, this phenomenon converted into workaholism which significantly endangered human health through creating stress and job burnout [3]. In this regard, the present study aims to investigate the relationship of workaholism with stress and job burnout.

The term workaholism was first used in 1968 by Wayne Oates, an American pastor and psychologist, in his book entitled "Confessions of a Workaholic". In his point of view, workaholics were those who needed to work so extreme that might cause serious threats to their health, personal happiness, interpersonal relationships and social responsibilities and roles, since they had irrational commitments to work hard and they voluntarily devoted a great amount of time to their work. Spence and Robbins (1992) offered the first academic and practical definition of the term "workaholism”. From their perspective, workaholism originated from a series of people's attitudes and perceptions. They considered a person workaholic when he/she was highly involved with his/her work. He/she had extraordinary inner compulsion to work hard and scantly enjoyed his/her work [4].

According to the typology, Spence and Robbins (1992) characterized workaholism by the amount and degree of the following components: 1 . Work involvement; 2 . Feeling of being driven to work; and 3. Work enjoyment. In workaholics, the degree of work involvement was really high and they were really eager to work; however, they barely enjoyed their work [4]. In contrast, people who were eager to work were involved with the work and enjoyed it; however, they did not have any excessive tension towards it. Scott, Moore, and Miceli (1997) identified three workaholism patterns including compulsive-dependent, perfectionist, and achievement-oriented [5]. Compulsive-dependent workaholics experienced a lot of anxiety and stress. Their work caused various physical and psychological problems. These people had low levels of satisfaction with their life and job and had low job performance. Perfectionist workaholics experienced a high level of stress, mental and physical problems, established hostile and ineffective interpersonal relations, had many absents and turnovers voluntarily and had low job satisfaction and job performance. Finally, achievement-oriented workaholics had high levels of job satisfaction, life satisfaction, mental and physical health, job performance and organizational citizenship behaviors and they had low stress and low voluntarily turnovers.

Occupational stress was initially considered by Hans Selye, emphasizing its importance in the educational environments. Occupational stress is the interaction between working conditions and an employee in a way that the person cannot cope with related pressures which endanger the mental health of the employee and result in physical burnout and job dissatisfaction [6]. In general, stress has greatly been taken into the consideration in recent years such that this century is known as the age of stress. Teaching profession is one of the most stressful professions and in this regard, over the past thirty years in various countries, a large number of researchers have expressed the concern that teachers experience severe stress and conducted different studies on this matter. In terms of responsibility for students' welfare and well-being, teachers have a unique profession. This is why teachers experience a different form of stress which needs to be defined. Teachers' occupational stress can be defined as negative and unpleasant emotions including anger, hopelessness, anxiety, depression, and nervousness which are created as the result of their occupation. Stress is a common phenomenon in the teaching profession. All teachers have been reported some degrees of occupational stress from mild to severe in different time periods. Based on previously conducted studies, teaching is regarded as one of the world's top ten most stressful careers and one-third of teachers believe that teaching is highly stressful [7]. Moreover, these studies reported high levels of job dissatisfaction and depression among teachers, mentioning that stress is a part of teaching. While some degrees of stress can increase and improve people's performance, high levels of stress can lead to numerous consequences such as physical illnesses and mental fatigue. If stress persists, in long term, it can endanger personnel's health and alter them to impotent and incapable people, the negative impacts of which are 
reflected in their performance [8]. Accordingly, stress management aids teachers to improve their physical, psychological, social and occupational performance.

Burnout contains fatigue and exhaustion in jobs helping people, especially social work professions. As stated in Amiri, Asadi, and Delbari Ragheb (2011), Jackson and Maslesh mentioned that burnout includes a feeling of losing energy, powerlessness, incapability, despair, failure and disability [9]. It is a state of physical, emotional and mental exhaustion in repose to stressors in an organization. Emotional exhaustion refers to an individual's reduction of emotional ability when the person does not have enough energy to perform his/her tasks. In depersonalization, people feel indifferent towards their job, performance, and colleagues. In the lack of personal accomplishment, people's perception of their abilities decrease and in this case, they cannot fulfill their responsibilities like before [10]. Burnout has various stages. In the first stage, a person loses his/her feelings. In the second stage, he/she experiences the deterioration of character or depersonalization. In the final stage, he/she considers himself/herself useless and inefficient, despises his/her work and thinks that no one appreciates his/her efforts, considering himself/herself unsuccessful. These feelings may cause negative attitudes towards the person, his/her job and life. These attitudes may decrease his/her occupational performance, interaction with others, level of commitment, and job satisfaction and increase his/her absences and turnovers [11].

Considering what was mentioned earlier, it can be accepted that one of the most significant indicators of organizations' success, in addition to financial resources, is employing healthy, capable, and committed labor force. Particularly in a profession like teaching in which one provides some human services, this issue is of great importance. In addition to external rewards, teachers, due to intrinsic motivations, somehow become workaholics [12]. Moreover, due to the nature of their job, teachers are encountered with various stressors, such as insufficient salaries and students' lack of interest in education; however, the main problem occurs when teachers' capabilities are not sufficient for fulfilling their workplace demands [13], such that these stressors may eventually lead to job burnout. Therefore, the main issues of this research were to indicate how is the status of elementary school teachers in Zahedan, considering workaholism, stress and job burnout? And what is the relationship of workaholism with stress and job burnout of elementary school teachers in Zahedan?

\section{Methods}

The present study had two main aspects: objectives and methods of collecting data. This was an applicable study. Moreover, considering the main issue of the current study, i.e. examining the relationship of workaholism with teachers' stress and job burnout, this study was a descriptive-correlational study (using regression) with regard to the relationship between the variables. The statistical population included all elementary school teachers in Zahedan in the academic year 2014-2015 ( $\mathrm{N}=3756)$. Using cluster and stratified random sampling methods proportional to the size, based on the Cochran's formula, 350 elementary school teachers (80 males and 270 females) were selected. In this study, three questionnaires were used to collect data.

A. Spence and Robbins' Workaholism Inventory (1992): This inventory includes 20 questions and 3 components including work involvement (6 questions), feeling of being driven to work (7 questions), and work enjoyment (7 questions). This inventory is designed based on a 5-point Likert type scale and is scored from 1 (totally disagree) to 5 (totally agree). Closer scores to 100 indicate symptoms of workaholism and vice versa.

B. Dua's Occupational Stress Survey (1994): This survey contains 21 items which examine employees' job stress. This scale is designed based on a 5-point Likert type scale and is scored from 1 (completely agree) to 5 (completely disagree). Closer scores to 105 show symptoms of having more occupational stress and vice versa.

C. Job Burnout Inventory of Alexander-Stamatios et al. (2003): This Inventory includes 20 questions that investigate job burnout. This scale is designed based on a 5-point Likert type scale and is scored from 0 to $4(0=$ never, 1 = sometimes, 2 = half of the time, $3=$ usually, and $4=$ always). Closer scores to 80 show symptoms of having more job burnout and vice versa.

To examine the validity of these questionnaires, content validity was applied. In this regard, the validity of these questionnaires was confirmed by professors of psychology at University of Sistan and Baluchestan, ensuring that these questionnaires evaluate the attributes considered by the researcher and are valid. To determine their reliability, Cronbach's alpha coefficient was used, the results of which are presented as follows: work involvement (0.641), feeling of being driven to work (0.619), work enjoyment (0.644), workaholism (0.671), occupational stress (0.814), and job burnout (0.76). These coefficients indicated that these questionnaires have the required reliability. The obtained data was analyzed in both descriptive and inferential levels. In the descriptive 
level, frequency, percentage,

\section{Results}

In the current study, 350 elementary school teachers participated, among which $77.1 \%$ were females, $84.86 \%$ were married, $56.9 \%$ had a BA degree and $70.41 \%$ had more than 10 years of service. To realize the descriptive status of variables under study, mean and standard deviation were used, the results of which are presented in Table 1. This finding indicates that teachers' mean scores on all the variables under study are higher than the considered theoretical mean, i.e. 3 , which is worrying.

To answer the first research question, i.e. what is the relationship between workaholism and teachers' occupational stress? Pearson correlation coefficient and simultaneous multiple regression analysis were used, the results of which are presented in Table 2 and Table 3.

Based on the results demonstrated in Table 2, all correlation coefficients of workaholism and its three components with occupational stress are significant and positive $(p<0.01)$. Therefore, it is confirmed that workaholism and its components are significantly and positively related to teachers' occupational stress. It can be concluded that with an increase in teachers' workaholism, their occupational stress increases. To predict teachers' occupational stress based on the components of workaholism, simultaneous multiple regression analysis was used, the results of which are presented in Table 3.

Based on Table 3, the amount of $\mathrm{F}$ is significant at the level of 0.000 . Therefore, the null hypothesis, i.e. the regression is not significant, is rejected at the 0.99 confidence level and it is confirmed that the linear regression model fits. According to the regression model, the coefficient of determination of $R^{2}$ is equal to 0.559 , indicating that workaholism can explain $55.9 \%$ of the variance of occupational stress. Moreover, beta coefficient demonstrates that with one unit increase in work involvement, occupational stress increases 1.126, with one unit increase in feeling of being driven to work, occupational stress increases 0.503 , and with a unit increase in work enjoyment, occupational stress increases 0.886 .

To answer the second research question, i.e. what is the relationship between workaholism and teachers' job burnout? Pearson correlation coefficient and simultaneous regression analysis were applied, the results of which are presented in Table 4 and Table 5.

Based on the results demonstrated in Table 4, all correlation coefficients of workaholism and its three components with job burnout are significant and positive $(p<0.01)$. Therefore, it is confirmed that workaholism and

Table 1. Descriptive status of the variables under study.

\begin{tabular}{ccc}
\hline Variable & M & SD \\
\hline Work involvement & (from 5) & 0.71 \\
Feeling of being driven to work & 3.87 & 0.62 \\
Work enjoyment & 4.01 & 0.6 \\
Workaholism & 4.03 & 0.64 \\
Occupational stress & 3.97 & 0.74 \\
Job burnout & 3.33 & 0.79 \\
\hline
\end{tabular}

Table 2. Correlation coefficients of workaholism (and its components) with teachers' occupational stress.

\begin{tabular}{ccc}
\hline Variable & \multicolumn{2}{c}{ Occupational stress } \\
\cline { 2 - 3 } Work involvement & $R$ & Sig \\
\hline Feeling of being driven to work & 0.739 & 0.000 \\
Work enjoyment & 0.743 & 0.000 \\
Workaholism (the overall index) & 0.73 & 0.000 \\
\hline
\end{tabular}


Table 3. Results of regression analysis conducted to predict occupational stress based on components of workaholism.

\begin{tabular}{|c|c|c|c|c|c|}
\hline & \multicolumn{2}{|c|}{ Non-standard coefficients } & \multirow{2}{*}{$\begin{array}{c}\text { Standard coefficients } \\
\text { Beta }\end{array}$} & \multirow{2}{*}{$\mathbf{T}$} & \multirow{2}{*}{ Sig } \\
\hline & B & Std. error & & & \\
\hline Work involvement & 1.17 & 0.505 & 1.126 & 2.322 & 0.021 \\
\hline Feeling of being driven to work & 0.614 & 0.257 & 0.503 & 2.388 & 0.017 \\
\hline Work enjoyment & 1.08 & 0.532 & 0.886 & 2.032 & 0.043 \\
\hline
\end{tabular}

$R=0.748 ; R^{2}=0.559 ; \mathrm{F}=146.07 ; \mathrm{Sig}=0.000$.

Table 4. Correlation coefficients of workaholism (and its components) with teachers' job burnout.

\begin{tabular}{ccc}
\hline Variable & \multicolumn{2}{c}{ Job burnout } \\
\cline { 3 - 3 } Work involvement & $\mathrm{R}$ & Sig \\
\hline Feeling of being driven to work & 0.737 & 0.000 \\
Work enjoyment & 0.739 & 0.000 \\
Workaholism (the overall index) & 0.728 & 0.000 \\
\hline
\end{tabular}

Table 5. Results of regression analysis conducted to predict job burnout based on components of workaholism.

\begin{tabular}{|c|c|c|c|c|c|}
\hline & \multicolumn{2}{|c|}{ Non-standard coefficients } & \multirow{2}{*}{$\begin{array}{c}\text { Standard coefficients } \\
\text { Beta }\end{array}$} & \multirow{2}{*}{$\mathbf{T}$} & \multirow{2}{*}{ Sig } \\
\hline & B & Std. error & & & \\
\hline Work involvement & 1.313 & 0.54 & 1.185 & 2.429 & 0.016 \\
\hline Feeling of being driven to work & 0.566 & 0.275 & 0.436 & 2.057 & 0.040 \\
\hline Work enjoyment & 1.144 & 0.57 & 0.88 & 2.008 & 0.045 \\
\hline
\end{tabular}

$R=0.744 ; R^{2}=0.554 ; \mathrm{F}=142.92 ; \mathrm{Sig}=0.000$.

its components are significantly and positively related to teachers' job burnout. It can be concluded that with an increase in teachers' workaholism, their job burnout increases. To predict teachers' job burnout based on the components of workaholism, simultaneous multiple regression analysis was used, the results of which are presented in Table 5.

Based on Table 5, the amount of $\mathrm{F}$ is significant at the level of 0.000 . Therefore, the null hypothesis, i.e. the regression is not significant, is rejected at the 0.99 confidence level and it is confirmed that the linear regression model fits. According to the regression model, the coefficient of determination of $R^{2}$ is equal to 0.554 , indicating that workaholism can explain 55.4\% of the variance of job burnout. Moreover, beta coefficient demonstrates that with one unit increase in work involvement, job burnout increases 1.185, with one unit increase in feeling of being driven to work, job burnout increases 0.436 , and with a unit increase in work enjoyment, job burnout increases 0.88 .

\section{Discussion and Conclusion}

The present study aimed to examine the relationship of workaholism with stress and job burnout in elementary school teachers in Zahedan. The results of the current study indicated that workaholism and its components were significantly and positively related to teachers' occupational stress. The results of simultaneous multiple regressions demonstrated that workaholism could predict teachers' occupational stress. These findings were in line with the results of Shariat, Taboli, and Shokou Saljooghi (2012) [14], Schaufeli, Bekker, Vander Heijden, and Prins (2009) [15], Srivastava (2012) [16], Aziz and Cunningham (2008) [17], Morgan (2006) [18], Saiedi and Asadi (2012) [19], and Gholipur et al. (2008) [12]. To explain these findings, it could be noted that workaholism 
imposed a great pressure on a person, the consequence of which was occupational stress and as the result of occupational stress, the person's physical and mental energy gnawed. Due to threats caused for the resources including time, facilities, social opportunities and supports, the individual became exhausted. Other words, workaholism imposed a great burden on the individual and this burden increased tension, fatigue, and burnout and decreased job satisfaction. Teachers had numerous tasks and as a result of high workload and a wide variety of duties they had, they bear a high level of working pressure. On the other hand, lack of promotion opportunities for this group imposed them to occupational stress. Workaholic teachers spent most of their time and energy at work and devoted little time to their life and other matters. In fact, these people neglected their need to rest and ignored other issues related to their daily life which might lead to incidence of some negative emotions impacting one's behavior and progress. Additionally, with increasing school responsibilities and altering its environment to a more complex one, teachers were expected to perform their tasks in a whole different level and this expectation put an increasing pressure on teachers endangering their health and personal comfort. Therefore, it was likely that teachers, in addition to external rewards, due to internal motivations became workaholics. These people usually devoted most of their time to their educational and professional work. This was why they became workaholics and as a result they experienced higher levels of stress and involvement with their work [12].

Morgan (2006) considered workaholism as the main reason causing anxiety and mental pressures in organizations and indicated that workaholism could lead to high blood pressure, stress, anxiety and occupational stress [18]. Robbinson (2007) stated that workaholism increased mental and physical illnesses and endangered an individual's health [20]. Anderson concluded that a person who experienced lower levels of workaholism (due to lower occupational stress) had better mental and physical health and had a better opportunity to improve himself/herself [21]. Mudrak stated that although workaholics mighty enjoy their work, work enjoyment was not regarded as a core component of workaholism. People who worked under pressure might not do their job based on their interests and willingness; however, due to high levels of pressure, they experienced a sense of tension, coercion and compulsion to work [22]. Workaholics experienced a lot of stress and anxiety, and were encountered with various physical and mental problems, had low levels of life and job satisfaction, and had low job performance (Scott et al., 1997). In addition, Karask demonstrated that if employees were allowed to control their work and the variable of control on the job was considered, employees would experience less stress and felt more committed to their job and organization [23].

Other findings of the current study indicated that workaholism and it components were significantly and positively correlated with teachers' job burnout. The results of simultaneous multiple regression analysis indicated that workaholism could predict teachers' job burnout. These findings are consistent with the results of Schaufeli et al. (2009) [15], Aziz and Cunningham (2008) [17], ShabaniBahar, and Mahmudiyan (2012) [21], Burke and Kraut (2009) [24], Taris [25], and Robbinson (2007) [20]. To explain these results, it can be noted that workaholics resist on working to improve themselves and to become satisfied and they search for happiness and joy in their work. These people have strong intrinsic motivation to work, against which they cannot resist. This independent motivation may cause due to environmental conditions including financial situations, atmosphere of the organization, pressure caused by one's administrator, job promotion and/or escaping from the family. Since workaholics have destructive behaviors, their behaviors may cause various physical and psychological consequences and impact their relations. These people spend a little time to rest and over time, they become exhausted cognitively and emotionally. Since they always work, even when they are not at work, they experience sympathetic arousal and become emotionally disturbed and as a result, they mostly report various mental disorders and physical complaints. When a person suffers from burnout, he/she is permanently tired, aggressive, cynical, and angry. He/she has negative thoughts and is irritable and bored. He/she becomes angry with the slightest discomfort, and is frustrated and feels hopelessness. Teachers who are eager to spend a lot of time at work enter their work lives into their personal lives unintendedly and usually loss the balance between their work lives and personal lives. Due to this severe exhaustion which is caused to the nature of teaching, teachers are faced with burnout symptoms including reduced effectiveness, fatigue, and spending a lot of time at work. As a result, workaholic teachers become exhausted faster and this in turn may affect the quality of their service and may lead to dissatisfaction of school administrators, students, and parents.

Workaholism is a kind of addiction which can be pleasant and at the same time tedious and problematic such that some researchers considered this state as a disease. These people do not necessarily love their jobs; however, they cannot live without it. They think that they are the only people who can handle that job and that they do the job in a pretty particular way. Due to this extreme indulge in work, they become workaholics. Since workaholics 
experience high workload including high occupational demands, little by little, they loss their mental energy [15], especially when employees increasingly involve themselves in the process of doing things and weaken themselves in this way. Meanwhile, since workaholics are not willing to delegate their power and duties, they are in conflict with their colleagues and as a result, their work becomes much more complicated. When workaholics spend a lot of time on doing their work, their energy is weakened and they suffer from occupational burnout [26]. In a study, Gholipur et al. (2008) indicated that people who are involved in their work are more prone to mental and physical traumas compared to others, since they devote a lot of mental energy and time to their work [12]. This means that they neglect their personal affairs and spend most of their time at work. Therefore, the more the intensity of the work and the more the job's demands, the more the employees' burnout. The results of this study are consistent with these results and showed that since workaholics are more involved with their work, they feel that they are more driven to work; hence, they are more prone to occupational burnout.

Overall, results showed that with increasing teachers' workaholism, they experience more stress and occupational burnout. Compulsive-dependent workaholics experience a lot of anxiety and stress. Their work causes various physical and psychological problems. These people have low levels of satisfaction with their life and job and have low job performance. Perfectionist workaholics experience a high level of stress, mental and physical problems, establish hostile and ineffective interpersonal relations, have many voluntary absents and turnovers and have low job satisfaction and job performance. Therefore, not only they experience stress, but also they experience occupational burnout. When workaholics spend a lot of time on doing their work, their energy is weakened and they suffer from occupational burnout [26]. Therefore, not only these people harm themselves, but also they harm their organization. In this regard, attempting to find a solution to decrease this phenomenon and it consequences seems essential. Considering the results of the current study, holding training courses for teachers to become familiar with the phenomena of workaholism, stress, job burnout, individual and organizational outcomes, methods of dealing with them and managing time effectively (aiding at devoting time to work, family and oneself) is of great importance. It is recommended that other researchers conduct studies to investigate other educational levels and other organizations and also examine the relationship of workaholism with other occupational consequences based on demographic characteristics (gender, age, marital status, level of education, etc.). These studies can be conducted using a qualitative method or both qualitative and quantitative methods. Moreover, since the questionnaires used in this study were developed in other countries, developing such questionnaires in accordance with the condition of our country is highly recommended. Since this study was carried out on elementary school in Zahedan, hence, generalizing its results has its own limitations. Therefore, when generalizing these results to other teachers and employees, great caution should be taken.

\section{References}

[1] Ahmadi, P., Tahmabi, R., Babashahi, J. and Fatahi, M. (2010) The Role of Personality Factors in Workholism Formation. Transformation Management Journal, 2, 46-67.

[2] Burke, R.J., Oberklaid, F. and Burgess, Z. (2006) Workaholism among Australian Women Psychologists: Antecedents and Consequences. International Journal of Management, 21, 263-277.

[3] Askari, A. and Nouri, A. (2011) Investigating the Relationship between Workaholic and Dimensions of General Health in the Employees of an Organization in Isfahan. Iran Occupational Health, 8, 237-245.

[4] Spence, J.T. and Robbins, A.S. (1992) Workaholism: Definition, Measurement, and Preliminary Results. Journal of Personality Assessment, 58, 160-178. http://dx.doi.org/10.1207/s15327752jpa5801_15

[5] Scott, K.S., Moore, K.S. and Miceli, M.P. (1997) An Exploration of the Meaning and Consequences of Workaholism. Human Relations, 50, 287-314. http://dx.doi.org/10.1177/001872679705000304

[6] Keramati, M.R. (2012) The Relation between Teachers’ Perception of School Atmosphere and Their Occupational Stress. Quarterly Journal of Business Management, 8, 103-140.

[7] Allison, M.G. (2007) Identifying the Types of Student and Teacher Behaviors Associated with Teacher Stress. Teaching and Teacher Education, 23, 624-640. http://dx.doi.org/10.1016/j.tate.2007.02.006

[8] Pourghane, P., Sharifazar, E., Zaersabet, F. and Khorsandi, M. (2010) Survey the Effect of Religious Beliefs in Stress Reduction in Students of Langroud Faculty of Medical Sciences. Journal Holistic Nursing and Midwifery, 20, 10-15.

[9] Amiri, M., Asadi, M.R. and Delbari Ragheb, F. (2011) Identification and Ranking Effective Factors on the Internet Shopping use of Fuzzy ANP. Quarterly Journal of Business Management, 3, 37-56.

[10] Rostami, A., Noruzi, A., Zarei, A., Amiri, M. and Soleimani, M. (2008) Exploring the Relationships between the Bur- 
nout and Psychological Wellbeing, among Teachers While Controlling for Resiliency and Gender. Iran Occupational Health, 5, 68-75.

[11] Amiri, H., Mirhashemi, M. and Parsamoein, K. (2011) Relationship between Perceived Job Characteristics, Job Roles and Burnout. Journal of Modern Industrial/Organization Psychology, 2, 53-69. (In Persian)

[12] Gholipur, A., Nargeseyan, A. and Tahmasbi, R. (2008) Workaholism: The New Challenge of Human Resource Management. Danesh e Modiriyat, 21, 91-110. (In Persian)

[13] Talaei, A., Mokhber, N., Mohammad Nejad, M. and Samari, A.A. (2008) Burnout and Its Related Factors in Staffs of University Hospitals in Mashhad. Koomesh, 9, 237-245. (In Persian)

[14] Shariat, H., Taboli, H. and Shokuh Saljooghi, Z. (2012) The Relation between Workaholism \& Occupational Stress: A Case Study about Welfare Organization Personnel of Kerman, Iran. Interdisciplinary Journal of Contemporary Research in Business, 4, 151-168.

[15] Schaufeli, W.B., Bakker, A.B., Vander Heijden, F.M. and Prins, J.T. (2009) Workaholism, Burnout and Well-Being among Junior Doctors: The Mediating Role of Role Conflict. Work and Stress, 23, 155-172. http://dx.doi.org/10.1080/02678370902834021

[16] Srivastava, M. (2012) Stress, Workaholism and Job Demands: A Study of Executives in Mumbai. NMIMS Management Review, XXII, 94-116.

[17] Aziz, S. and Cunningham, J. (2008) Workaholism, Work Stress, Work-Life Imbalance: Exploring Gender's Role. Gender in Management: An International Journal, 23, 553-566. http://dx.doi.org/10.1108/17542410810912681

[18] Morgan, G. (2006) Images of Organization. Sage Publications, London.

[19] Saiedi, L. and Asadi, A. (2012) Workaholism, Work Stress. Journal of Management, 23, 32-37. (In Persian)

[20] Robbinson, B.E. (2007) Chained to the Desk: A Guidebook for Workaholics, Their Partners and Children, and the Clinicians Who Treat Them. New York University Press, New York.

[21] ShabaniBahar, G. and Mahmudiyan, Z. (2012) The Relationship between Workaholism and Job Burnout of Sport Teachers in Kermanshah. Journal of Sport Management and Motor Behavior, 8, 129-147. (In Persian)

[22] Hasani, M. and Shohudi, M. (2013) The Relationship between the Components of the Circuit's Security Leadership and Mental Security with Dimensions of Workaholism: Urmia University Personnel. Journal of Executive Management, 5, 85-106. (In Persian)

[23] Khaef Elahi, A.A., Nargesian, A. and Babashahi, J. (2012) Investigating the Relationship between Workaholism and Organizational Citizenship Behavior (Case of: Nurses in Tehran City). Transformation Management Journal, 4, 21-37. (In Persian)

[24] Burke, M. and Kraut, R. (2008) Mopping up: Modeling Wikipedia Promotion Processes. Proceedings of the 2008 ACM Conference on Computer Supported Cooperative Work, San Diego, 8-12 November 2008, 27-36. http://dx.doi.org/10.1145/1460563.1460571

[25] Taris, T.W., Schaufeli, W.B. and Verhoeven, L.C. (2005) Workaholism in the Netherlands: Measurement and Implications for Job Strain and Work-Nonwork Conflict. Applied Psychology: An International Review, 54, 37-60. http://dx.doi.org/10.1111/j.1464-0597.2005.00195.x

[26] Sonnentag, S. and Zijlstra, F.R. (2006) Job Characteristics and Off-Job Activities as Predictors of Need for Recovery, Well-Being, and Fatigue. Journal of Applied Psychology, 91, 330-350. http://dx.doi.org/10.1037/0021-9010.91.2.330 